\title{
Improved method for separation of silver nanoparticles synthesized using the Nyctanthes arbor-tristis shrub
}

\author{
Aakash Gupta1, Agni Raj Koirala², Bikash Gupta \& Niranjan Parajuli*, \\ ${ }^{1}$ Central Department of Chemistry, Tribhuvan University, Kirtipur, Nepal \\ ${ }^{2}$ Korea Center for Artificial Photosynthesis, Sogang University, South Korea \\ ${ }^{3}$ Department of Physics, Patan Multiple Campus, Tribhuvan University, Lalitpur, Nepal \\ *Corresponding author: nparajuli@cdctu.edu.np
}

\section{DOI: 10.2478/acmy-2019-0005}

\begin{abstract}
:
Plant-mediated synthesis of silver nanoparticles through green chemistry approach has evolved into a new era of research; however, the heterogeneous size and dispersity of silver nanoparticles have limited its applications, such as surface-enhanced Raman scattering, plasmon resonance, and more specifically in the medical field of target drug delivery and therapeutic activity. Here-we investigated the effect of purification and separation modes on the dispersity, size, and morphology of silver nanoparticles, synthesized by plant extract (Nyctanthes arbor-tristis). Transmission electron microscopy revealed silver nanoparticles with an average diameter of $13.0 \mathrm{~nm}$ when synthesized through ethanol precipitation, which is advantageously smaller. This result suggests that the silver nanoparticles size can be fine-tuned by changing the separation mode during purification from plant extract. Due to uniformity, our obtained nanoparticles can be expected to show higher catalytic activity towards photochemical reactions, drug delivery and antibacterial activity due to the absence of inactive coating layer (capping agent).
\end{abstract}

Keywords: Silver nanoparticles, separation mode, precipitation, uniform, plant extract.

\subsection{Introduction:}

Noble metal nanoparticles like silver, gold, palladium, platinum, and copper have received great attention due to their wide range of application in biomedicals, sensors, antimicrobials, catalysts, and bio-labeling. Their properties such as mechanical, catalytic, electronic and optical [1] completely depend upon the particle's size, [2-4] shape, [5,6] surrounding medium, [7] and aggregation state. [6] Among all noble metal nanoparticles, silver is most effective for antimicrobial activities and less toxic to animal cells. [8] It has attracted more research interest due to its diverse medical properties and therapeutic applications such as antiangiogenic effects,[9] inducing apoptotic signalling,[10] inducing cytotoxicity and genotoxicity in human lung cancer cells, [11] and Dalton lymphoma ascites tumor cells, [12] treatment of HIV-1 virus, [13, 14] inhibition of in-vitro production of Hepatitis B virus RNA and extracellular virions, [15] inhibition in replication of respiratory syncytial virus, [16] herpes simplex virus type 1, [17] monkeypox virus [18] and retinal neovascularization. [19] Therefore, silver nanoparticles can be developed to combat these diseases as an alternative means to expensive drugs. Ag NPs can be effectively functionalized with biomolecules such as nucleic acid, [20-26] for gene therapies, antisense oligonucleotide, [20, 22] proteins, [24, 27] small molecule therapeutics, [27-29], and siRNA [22, 30,31] to use them as a targeted drug vehicle in-vivo for controlled and targeted release of drugs. It has been evidenced that the Ag NPs of size range 1-10 nm undergo size-dependent interaction with HIV-1 virus. [32] It has been established that the antimicrobial activities are shape-dependent [33] and also revealed that the antibacterial efficiency was greatly enhanced by the Ag NPs of size less than the $10 \mathrm{~nm}$ and their maximum efficacy was obtained for $5 \mathrm{~nm}$ size. [34] However, several parameters affect the control over the size, morphology, and distribution during the synthesis of Ag NPs. For example, the research study [35] revealed that the size, shape, and morphology of Ag NPs are affected by the metal ion concentration, extract composition, and reaction time. Besides these variables, synthesis temperatures $\left(30^{\circ} \mathrm{C}-90^{\circ} \mathrm{C}\right)$ can alter the nanoparticle nucleation rate [36] and affect the size and dispersity of Ag NPs [37]. Current Ag NP synthesis methods include harnessing the power of plants in a green chemistry approach and an abundance of literature has established the synthesis procedure of Ag NPs through the biosynthesis route using extracts from plants such as Annas comosus, [38] Ceratonia siliqua, [39] Mullberry, [40] Nicotiana tobaccum, [41] Rhizophora mucronata, [42] Solanum xanthocarpum, [43] Acacia leucophloea, [44] and Verbena officinalis. [45] These methods use a common centrifugation approach to purify the nanoparticles. But, the Ag NPs synthesized by this approach have remarkable variability in Ag NPs properties like dispersity and morphology, due to the mode of separation. Gupta et al. [46] reported the synthesis of Ag NPs using Taraxacum officinale with purification through either centrifugation or ethanol precipitation, and found that the average size of Ag NPs was found to be $33.6 \mathrm{~nm}$ in the centrifugation method but only half as large $16.8 \mathrm{~nm}$ in the case of ethanol precipitation and suggested the latter as an efficient purification method.

During plant extract synthesis process, two different purification methods can be used. In the solvent precipitation method, the nanoparticles are obtained directly by evaporating the solvent or precipitation. [46] The nanoparticles obtained by this method are well dispersed, separated and somewhat uniform (little variation in size and shape). Conversely, in the ultracentrifugation method, the nanoparticles are isolated by centrifuging large volumes of solution at a high speed of 8000-20000 rpm to separate out small-sized Ag NPs. [39] During this process, it has been found that the particles are mostly aggregated, non-uniform in both size and shape (with a wide variation in dispersity). [39, 40] Compared to the precipitation method, [46] the centrifugation method is also a time consuming and rigorous mode of separation. Centrifugation often results in high losses of the extremely small size nanoparticles, which leads to lower yields compared with the solvent precipitation method. We have previously shown the ethanol precipitation method to be effective in Ag nanoparticle synthesis in T. officinale [46], including uniform shape, size, and dispersity. Therefore, we have focused the current study on "ethanol precipitation" method of Ag NPs separation.

We chose the Nyctanthes arbor-tristis night-flowering jasmine shrub as the biosynthesis host, a plant whose Ag NP synthesis properties have been established. Leaves of this plant contain following phytoconstituents such as for D-mannitol, $\beta$-sitosterol, Flavanal glycosides-Astragaline, Nicotiflorin, Oleanolic acid, Nyctanthic acid, tannic acid, ascorbic acid, methyl salicylate, glucose, and fructose. [47] Basu et al., reported the biosynthesis of Ag NPs with a size range of 50-80 $\mathrm{nm}$ using the aqueous seed extract of $N$. arbor-tristis, [48] while Gogoi et al. reported Ag NPs with a smaller size range 5-20 nm through ethanolic flower extract. [49] Similarly, Chandra et al., synthesized Ag NPs with a size range of $15-20 \mathrm{~nm}$ using a leaf extract of $N$. arbor-tristis but with a wide range of variation [50]. Srinivasan et al. also synthesized Ag NPs with sizes ranging from 28-30 nm (confirmed from SEM image) using an N. arbortristis leaf extract [51]. Rout et al., also biosynthesized Ag NPs using a leaf extract of N. arbor-tristis with an average size of 20 nm. [52] However, their TEM study used the crude Ag NP colloidal solution without separation or purification, which known to affect the particle size.

Here, synthesis of Ag NPs uses a green chemical approach to tightly control the size, shape, and dispersity as the most important characteristics of noble metal nanoparticles using plant extract approach. We investigated the synthesis of Ag NPs using $N$. arbor-tristis leaf extract as capping and reducing agent and separation through ethanol precipitation, to compare their size, shape, and dispersity with previous reports. This method uses the plant extract source as like other method but change in method of separation with ethanol has positively affected the properties of synthesized silver nanoparticles that are bolstered by the UV-Vis spectroscopy, X-ray powder diffraction (XRD, Attenuated total reflection-Fourier-transform infrared spectroscopy (ATR-FTIR), Scanning electron microscopy (SEM), and Transmission electron microscopy (TEM) analysis which is the central idea of this study. Consideration from the uniformity and method of separation aspects, the present study was designed to synthesize uniform size Ag NPs through Green Chemistry route without the use of any additional surfactant or capping agent. This present method will improve the currently existing methods employed in green biosynthesis approach of silver nanoparticles.

\subsection{Experiment Section}

Silver nitrate as a source of Ag+ ions for Ag NPs and ethanol were purchased from Thermo Fischer Scientific, USA. All chemicals were used without further purification. Leaves of N. arbor-tristis plant were obtained from Tribhuvan University Garden (Kathmandu, Nepal). In a typical Ag NP synthesis procedure, 
the plant extract was prepared by washing $20 \mathrm{~g}$ of fresh leaves in distilled water two to three times, cut into fine pieces, and boiled in $100 \mathrm{~mL}$ of distilled water for 10-12 minutes followed by cooling to room temperature and filtered through Whatman No1 filter paper. Here, the filtrate acts as a reducing and stabilizing agent. Then, $10 \mathrm{~mL}$ of this freshly-prepared plant extract was mixed dropwise with $90 \mathrm{~mL}$ of $1 \mathrm{mM}$ and $2 \mathrm{mM} \mathrm{AgNO} \mathrm{O}_{3}$ aqueous solution with constant stirring and the reactant mixture was kept at room temperature for $24 \mathrm{hrs}$ for the reduction of $\mathrm{Ag}_{+}$ions to $\mathrm{Ag}$ by the biomolecules present in the leaf extract.

For further analysis, synthesized crude Ag NPs were analyzed with a UV-Visible spectrometer (Thermo Scientific GENESYS 10 Vis-UV, resolution \pm 2 nm, range 350-700 nm). Purification by solvent precipitation was carried out by adding $10 \mathrm{~mL}$ of ethanol to $100 \mathrm{~mL}$ of crude extract solution, and finally drying in a hot air oven at $25-26^{\circ} \mathrm{C}$. Pure, dried Ag NPs were stored in airtight plastic tubes covered with aluminum foil until further analysis.

Ethanol-precipitated Ag NPs were subjected to XRD analysis (Rigaku D/DMAX-2500/pc diffractometer) at a monochromatic CuK $\alpha$ radiation of $\lambda 1.54060$ $\AA ̊$ and a $2 \theta$ range scanning range of $20^{\circ}-90^{\circ}$. ATR-FTIR analysis was also performed (Nicolet iS50 FT-IR spectrometer with DTGS detector) by co-adding 32 scans at a resolution of $4 \mathrm{~cm}-1$ from range $4000-500 \mathrm{~cm}-1$. SEM analysis was carried out on an FE-SEM Hitachi S4300 at an acceleration voltage of $20 \mathrm{kV}$, and TEM study was performed on a JEOL 2011 operated at $200 \mathrm{kV}$.

\subsection{Result and Discussion}

The synthesis and response of Ag NPs achieved by using plant extract route through ethanol precipitation method have been monitored through different characterization techniques which are explained below in detail.

\subsection{UV-Vis Spectroscopy analysis of Ag NPs.}

The change in color of crude extract solution from pale yellow to dark reddish-brown, along with a band around 400-450 nm in the UV-visible absorbance spectrum [53] acts as evidence of bioreduction of $\mathrm{Ag}^{+}$ions to $\mathrm{Ag}^{\circ}$. The absorbance maximum at $440 \mathrm{~nm}$ of the $\mathrm{N}$. arbor-tristis crude extract solution with 1 $\mathrm{mM} \mathrm{AgNO}_{3}$ after 4 hours of mixing (Figure 1) is consistent with the typical absorption peak shown in other Ag NPs studies [48, 49]. These phenomena are the consequences of surface plasmon resonance (SPR) which is the excitation of electrons in the conduction band due to absorption and scattering of light and these electrons have unique vibration mode depending upon shape and size of nanoparticles. So, they represent specific UV-visible absorption spectrum. It acts as an indication of reduction of $\mathrm{Ag}^{+}$ions due to the involvement of functional groups present in the biomolecules such as glycosides [48] of leaf extract which is corroborated by the ATR-FTIR and TEM analyses. It is the signature signal of spherical Ag NPs. [54] Broad peaks with lower absorbance in absorbance spectra are observed for large metal colloidal dispersion. [55] Here, peak is narrow with high absorbance showing the presence of smaller Ag NPs.

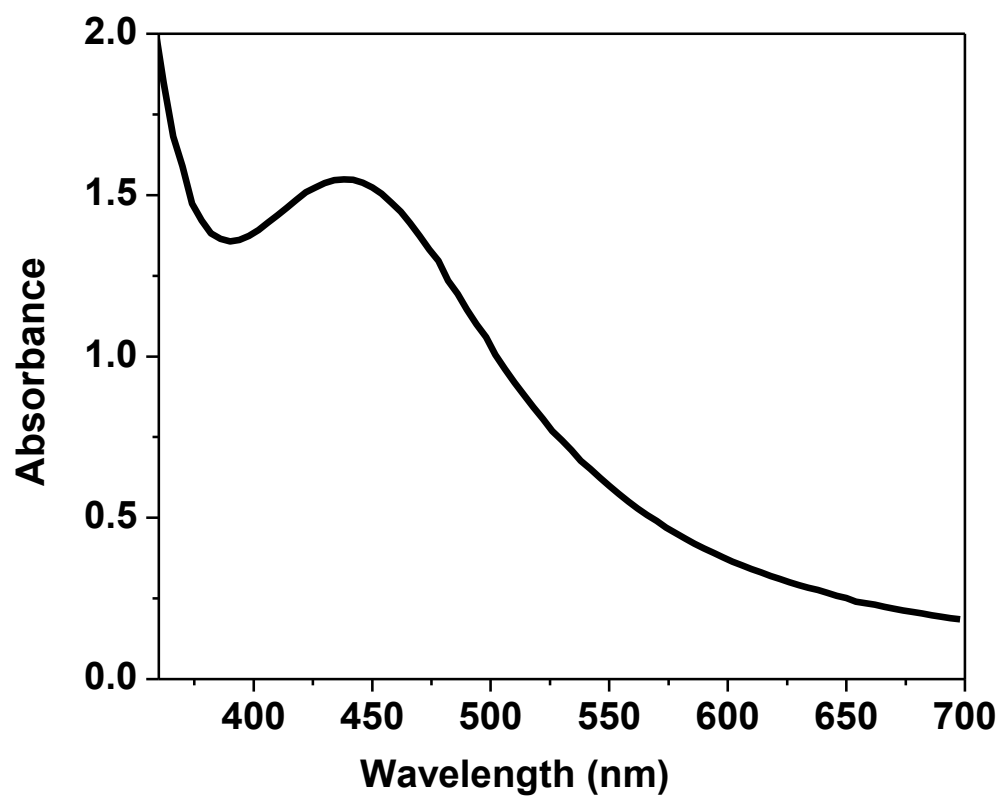

Figure 1: UV-visible spectrum of $90 \mathrm{~mL} 1 \mathrm{mM}$ AgNO3 plus $10 \mathrm{~mL}$ leaves extract of $N$. arbor-tristis after $4 \mathrm{~h}$ of mixing, indicative of Ag NPs synthesis

\subsection{X-ray Diffraction analysis of Ag NPs}

The XRD is used in the identification of crystalline material, as the diffraction pattern is unique for every crystalline material. The ethanol precipitated, $N$. arbor-tristis extract-synthesized Ag nanostructure is confirmed by the characteristic diffraction peaks observed at the $2 \theta$ angles $38.06^{\circ}, 44.24^{\circ}, 64.58^{\circ}$ and $77.38^{\circ}$ in the XRD pattern (Figure 2). These peaks are indexed as (111), (200), (220), and (311) respectively, and their crystallographic planes correspond to the characteristic face-centered cubic (fcc) silver lines in accordance with the study of Rout et al. [52], a value in good agreement with the powder data of JCPDS Card number 04-0783.

Several additional peaks were also observed in the diffraction pattern. These unassigned peaks may be from impurities during the preparation of extract filtrate [56] or may be due to bio-organic phases on the surface of Ag NPs. [57] Larger the broadening of peaks in the x-ray line spectrum, smaller will be the size of nanoparticles. Here, broad peaks also suggest the formation of small size of Ag NPs. The crystallite or grain domain size was found to be $8.38 \mathrm{~nm}$ measured from the Full width at half maximum (FWHM) of the (111) diffraction peak (x-ray line broadening) index obtained from the Gaussian fitting (shown in the inset of Figure 2), with the assumptions having free from non-uniform strains, using the Debye-Scherrer equation.

$$
\mathrm{t}=(\mathrm{K} * \lambda) /(\beta \operatorname{Cos} \theta)
$$

where, $\mathrm{t}=$ crystallite or grain size

$\mathrm{K}=$ dimensionless shape factor, with a value close to unity $(\sim 0.9)$

$\lambda=$ wavelength of the radiation, $(0.154 \mathrm{~nm}$ for $\mathrm{Cu} \mathrm{K} \alpha)$

$\theta=$ Bragg's angle (the $2 \theta$ value of chosen peak) and 
$\beta=$ full width at half maximum (should be in radian)

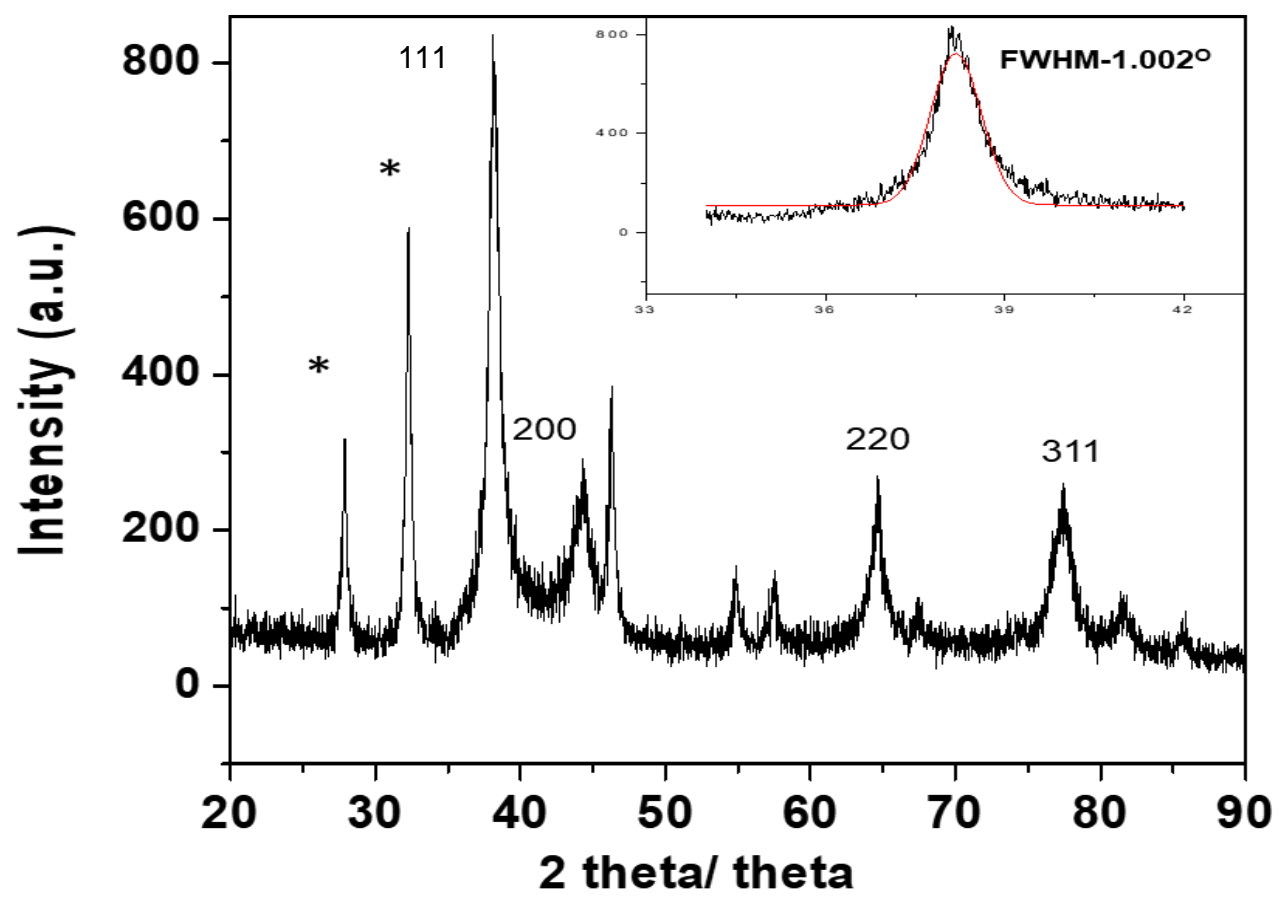

Figure 2: X-ray diffraction pattern of ethanol precipitated Ag NPs obtained from N. arbor-tristis extract with $\mathrm{Ag} \mathrm{NO}_{3}$, showing peaks consistent with the presence of Ag NPs. Indices are labeled above the peaks. Inset is the Gaussian fitting of the diffraction peak indexed as 111, with face-centered cubic lines in agreement with silver nanoparticles. FWHM is the Full width at half maximum in degree $(\stackrel{o}{)}$ obtained from Gaussian fitting

The relevant parameters were calculated from the experimental XRD data and compared with reference data as shown in Table 1 as like in previous studies [58]. Values are in agreement with standard JCPDS as well as TEM data. The lattice parameter, $\mathrm{d}$-spacing, reference, and experimental peaks are consistent with each other. The FWHM is obtained from each plane $(h k l)$ by Gaussian fitting which is used to calculate the grain domain size or crystallite size. The grain size was $8.38 \mathrm{~nm}$ for (111), $7.33 \mathrm{~nm}$ for (200), $8.30 \mathrm{~nm}$ for (220), and $12.37 \mathrm{~nm}$ for (311) peak and the average crystallite size were found to be 9.1 $\mathrm{nm}$ which is consistent with TEM results. This XRD result indicates that most of Ag NPs were uniform in diameter (7.33-8.38 nm) except $12.37 \mathrm{~nm}$ for the 311 plane which corroborates the formation of uniform Ag NPs through ethanol precipitation.

Table 1 Key XRD measurements of Ag NPs obtained using N. arbor-tristis leaf extract.

\begin{tabular}{|c|c|c|c|c|c|c|c|}
\hline $\begin{array}{l}\text { Reference Peaks } \\
\text { Position } \\
\text { (JCPDS 04-0783) }\end{array}$ & $\begin{array}{l}\text { Experim } \\
\text { ental } \\
\text { Peaks } \\
\text { Position } \\
(2 \theta)\end{array}$ & hkl & $\begin{array}{l}\text { FWHM ( } \beta \\
\text { in degree) } \\
(\stackrel{\circ}{)})\end{array}$ & $\begin{array}{l}\text { FWHM ( } \beta \\
\text { in radian) }\end{array}$ & $\begin{array}{l}\text { The } \\
\text { crystallite } \\
\text { size }(\mathrm{nm})\end{array}$ & $\begin{array}{l}\text { d-spacing } \\
\text { (Å) }\end{array}$ & $\begin{array}{l}\text { Lattice } \\
\text { parameter, a } \\
\text { in }(\AA ̊)\end{array}$ \\
\hline 38.116 & 38.06 & 111 & 1.00225 & 0.01749 & 8.38 & 2.361 & 4.089 \\
\hline 44.277 & 44.24 & 200 & 1.17002 & 0.02042 & 7.33 & 2.044 & 4.088 \\
\hline 64.426 & 64.58 & 220 & 1.13130 & 0.01975 & 8.30 & 1.441 & 4.075 \\
\hline 77.472 & 77.38 & 311 & 1.51361 & 0.02642 & 12.37 & 1.231 & 4.082 \\
\hline
\end{tabular}

\subsection{ATR-FTIR Spectroscopy analysis of Ag NPs}

The capping or reduction of $\mathrm{Ag}_{+}$to Ag NPs is due to the involvement of functional groups of biomolecules in the extract which was measured with ATR-FTIR spectroscopy (Figure 3). The broad and strong bands at 3195-3110 $\mathrm{cm}_{-1}$ are indicative of bonded hydroxyl groups $(-\mathrm{OH})$ or amine groups $(-\mathrm{NH})$. The peaks at 2890-2832 cm-1 are consistent with aliphatic $\mathrm{C}-\mathrm{H}$ stretching, and a peak detected around $2345 \mathrm{~cm}_{-1}$ indicates due to $\mathrm{C}=0$ asymmetric stretching of $\mathrm{CO}_{2}$, or $\mathrm{C} \equiv \mathrm{C}$ stretching. The peak at $1732 \mathrm{~cm}-1$ was attributed to the carboxyl group $(>\mathrm{C}=0)$ stretching vibration, and peaks at $1597,1567,1505 \mathrm{~cm}-1$ are correlated with amide II, which arose due to the $(>C=0)$ and amine $(-\mathrm{NH})$ stretching vibrations in amide linkages of proteins. Peaks at $1241 \mathrm{~cm}-1$ and 1005 $\mathrm{cm}_{-1}$ are likely due to an asymmetric and symmetric stretch of $\mathrm{C}-\mathrm{O}-\mathrm{C}$ and $\mathrm{C}-0$. The absorbance around $1365 \mathrm{~cm}_{-1}$ notably indicated the presence of residual $-\mathrm{NO}_{3}$ [59] or may be due to $\mathrm{C}-\mathrm{H}$ bending. The peak at $507 \mathrm{~cm}_{-1}$ was related to Ag NP bonding with the oxygen from $-\mathrm{OH}$ groups of extract biomolecules [60] such as the $-\mathrm{OH}$ groups in flavonol glycosides (reducing sugars), ascorbic acid, tannic acid, oleanolic acid, [44] and ethanol and amide linkages of proteins, which are responsible for the reduction and stabilization of Ag NPs. The $-\mathrm{OH}$ group involvement from FTIR spectrum is indicative of ethanol participation during purification or separation, playing a significant role in the production of controlled and uniform Ag NPs. 


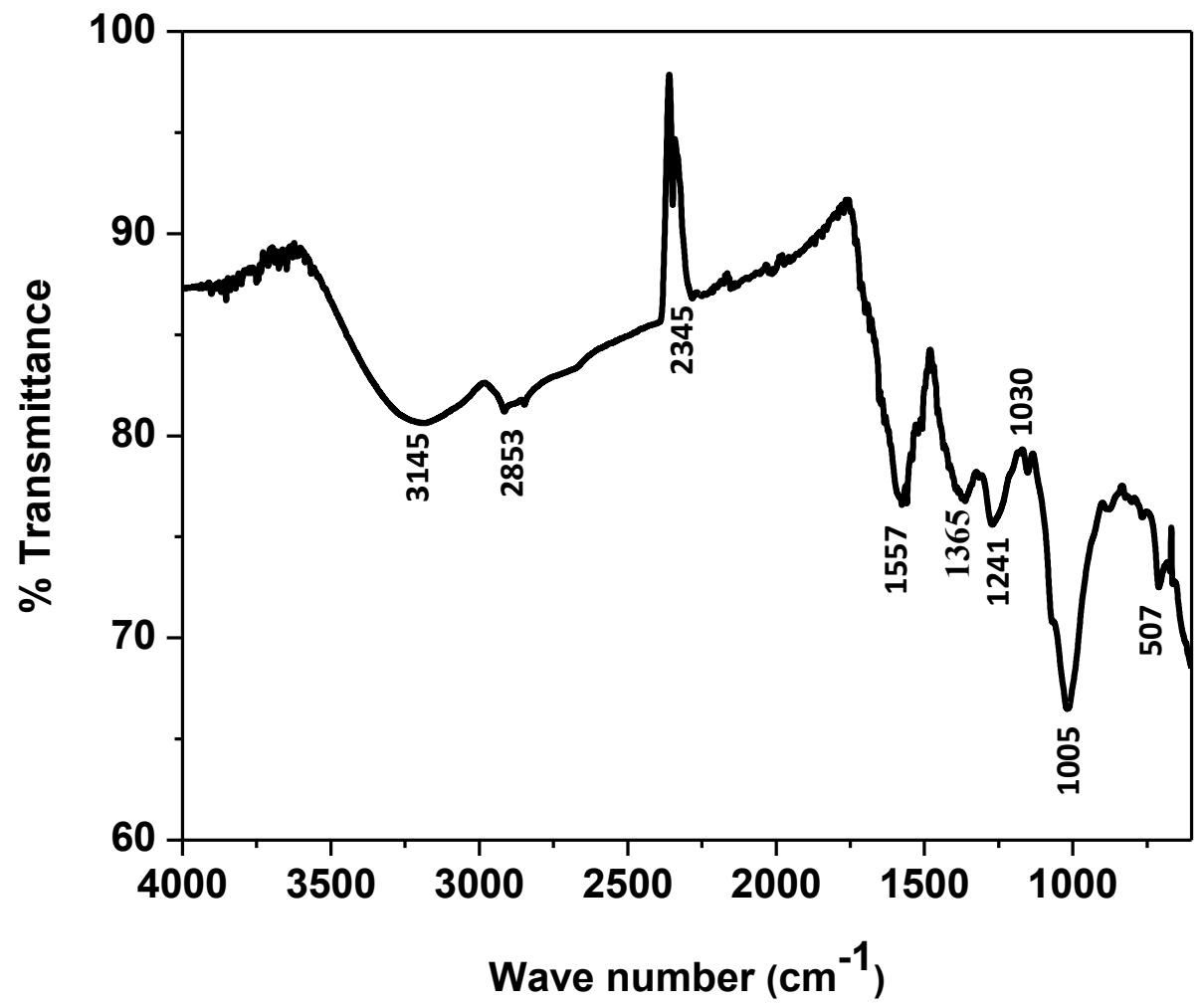

Figure 3: Attenuated total reflectance-Fourier transform infrared spectrum (ATR-FTIR) of Ag NPs synthesized from N. arbor-tristis. Bands observed from 4000-500 cm-1 for different functional groups responsible for reduction and stabilization

\subsection{Scanning Electron Microscopy (SEM) Analysis of Ag NPs}

Here, SEM is used for the investigation of surface morphology of nanoparticles. Scanning electron micrographs (SEM) for the Ag NPs synthesized from $N$. arbor-tristis extract with ethanol precipitation (Figure 4) revealed the encapsulation of Ag NPs by plant extract matrix. This clearly indicates the spherical morphology of silver Ag NPs coated by the extract. The size of the nanoparticles in SEM image looks larger than from TEM image due to Vander Waals cluster of small entities. [61]
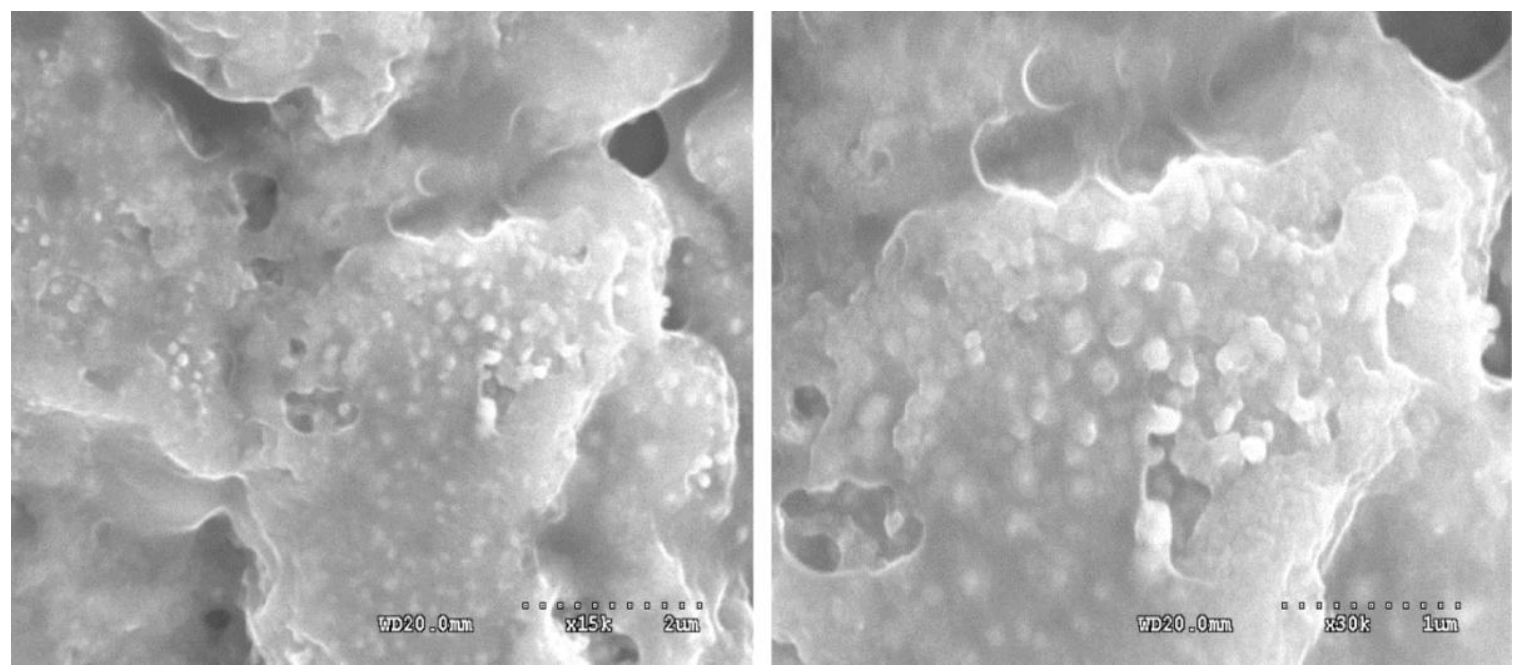

Figure 4: Scanning electron micrographs of Ag NPs synthesized from N. arbor-tristis with ethanol precipitation at $2 \mu \mathrm{m}$ (left) and $1 \mu \mathrm{m}$ (right) resolution. Micrographs show the encapsulation of Ag NPs in the extracted matrix.

\subsection{Transmission Electron Microscopy (TEM) and Selected Area Electron Diffraction (SAED) analysis of Ag NPs}

Transmission electron micrographs investigation (Figure 5 a-f) of the synthesized Ag NPs from leaf extract of $N$. arbor-tristis and purified through ethanol precipitation revealed the formation of mono-dispersed, spherical and uniform Ag NPs in diameter. The TEM images, especially at $5 \mathrm{~nm}$ resolution (Figure 5(f)) shows Ag NPs are stabilized or capped by biomolecules present in the leaf extract. Size uniformity is clearly observed in case of Ag NPs capped from $N$. arbor-tristis extract, suggesting a good source for the production of controlled and uniform size Ag NPs. 

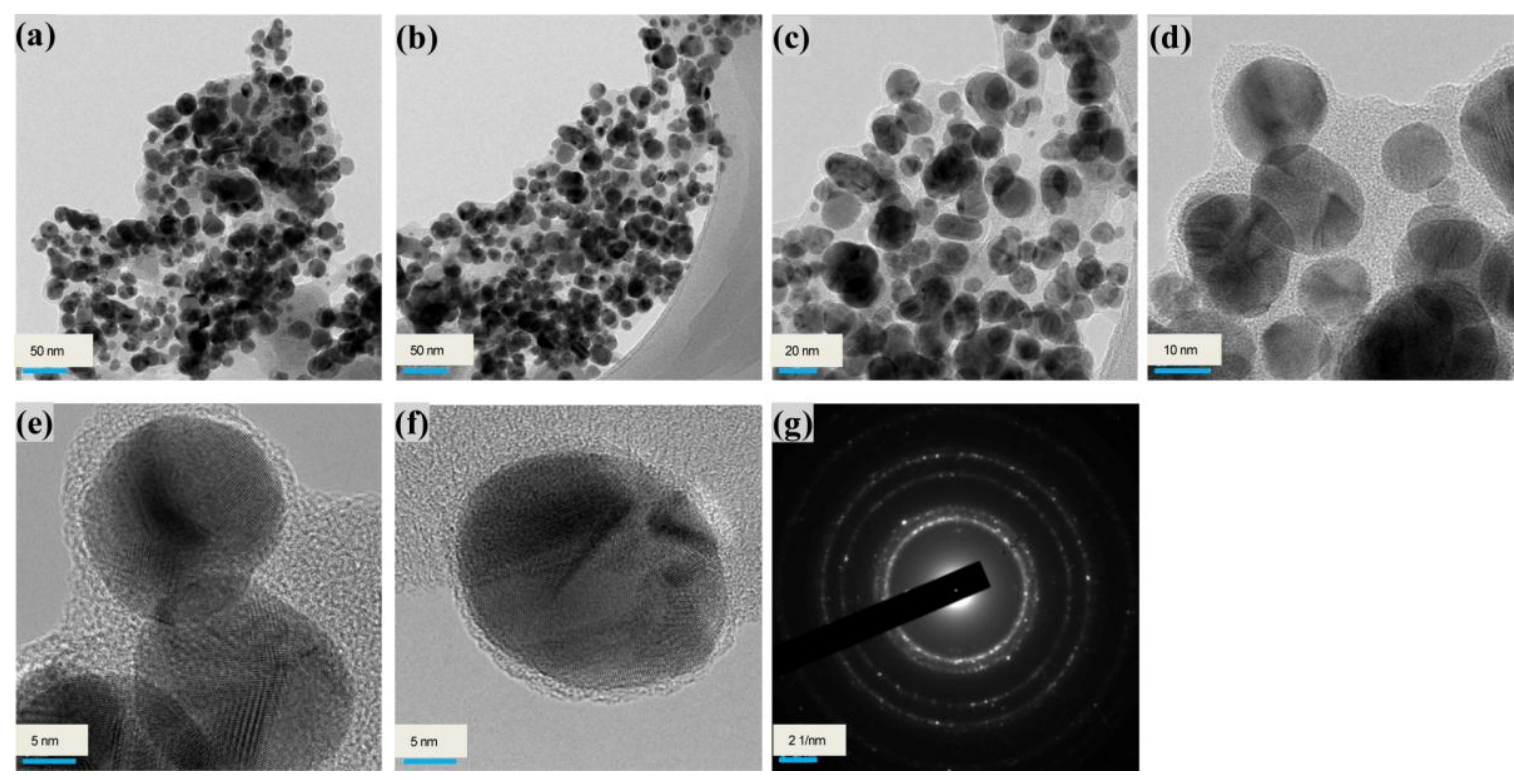

Figure 5: Transmission electron micrographs of representative Ag NPs synthesized from N. arbor-tristis through ethanol precipitation at different scale bars (a) and (b) $50 \mathrm{~nm}$ (c) $20 \mathrm{~nm}$ (d) $10 \mathrm{~nm}$ (e) and (f) $5 \mathrm{~nm}$ and (g) A selected area electron diffraction pattern of the Ag NPs.

The crystallinity of Ag NPs along with TEM was also confirmed by Selected Area Electron Diffraction (SAED) patterns depicted in Figure 5(g), which consist of circular rings with bright spots-indicating the highly crystalline nature of nanoparticles obtained through $N$. arbor-tristis extract. The d-spacing calculated from the selected area electron diffraction pattern and with X-ray diffraction pattern was matched with JCPDS database 04-783. These values are in close agreement with each other and the rings correspond to the (111), (200), (220), and (311) Bragg's diffraction planes for face centered cubic (fcc) structure of silver. The d-spacing determined from the diffraction pattern (Figure $5(\mathrm{~g})$ ) is shown in the following Table 2.

Table 2 Key SAED measurements of Ag NPs obtained using N. arbor-tristis leaf extract.

\begin{tabular}{|c|c|c|c|c|c|c|}
\hline $\begin{array}{l}\text { The diameter of } \\
\text { diffraction rings, } \\
(2 \mathrm{R}) \\
(1 / \mathrm{nm})\end{array}$ & $\begin{array}{l}\text { The radius } \\
\text { of } \\
\text { diffraction } \\
\text { rings, } R \\
(1 / \mathrm{nm})\end{array}$ & $\begin{array}{l}\text { d-spacing, } \\
1 / \mathrm{R} \\
(\mathrm{nm})\end{array}$ & $\begin{array}{l}\text { d-spacing } \\
\text { from SAED } \\
(\AA)\end{array}$ & $\begin{array}{l}\text { d-spacing } \\
\text { from XRD } \\
(\AA \AA)\end{array}$ & $\begin{array}{l}\text { d-spacing } \\
\text { JCPDS 04- } \\
0783 \\
(\AA ̊)\end{array}$ & hkl \\
\hline 8.5714 & 4.2857 & 0.2333 & 2.333 & 2.361 & 2.359 & 111 \\
\hline 9.5333 & 4.7666 & 0.2097 & 2.097 & 2.044 & 2.044 & 200 \\
\hline 13.3619 & 6.6809 & 0.1496 & 1.496 & 1.441 & 1.445 & 220 \\
\hline 16.1904 & 8.0952 & 0.1235 & 1.235 & 1.231 & 1.231 & 311 \\
\hline
\end{tabular}

The mean grain or crystallite size obtained from 200 particles counted from the TEM micrograph of 5(a)-Ag NPs synthesized through ethanol precipitation is $13.0 \mathrm{~nm}$ with a standard deviation of $4.8(13.0 \pm 4.8 \mathrm{~nm})$. The histogram (Figure 6) depicts that the majority of the Ag NPs are around $9 \mathrm{~nm}$ in diameter which is consistent with the average crystallite size obtained from the XRD analyses. The above micrographs and histogram clearly show the formation of smaller, uniform and mono-disperse silver nanoparticles from N. arbor-tristis through ethanol precipitation, endorsing the main idea of this investigation.

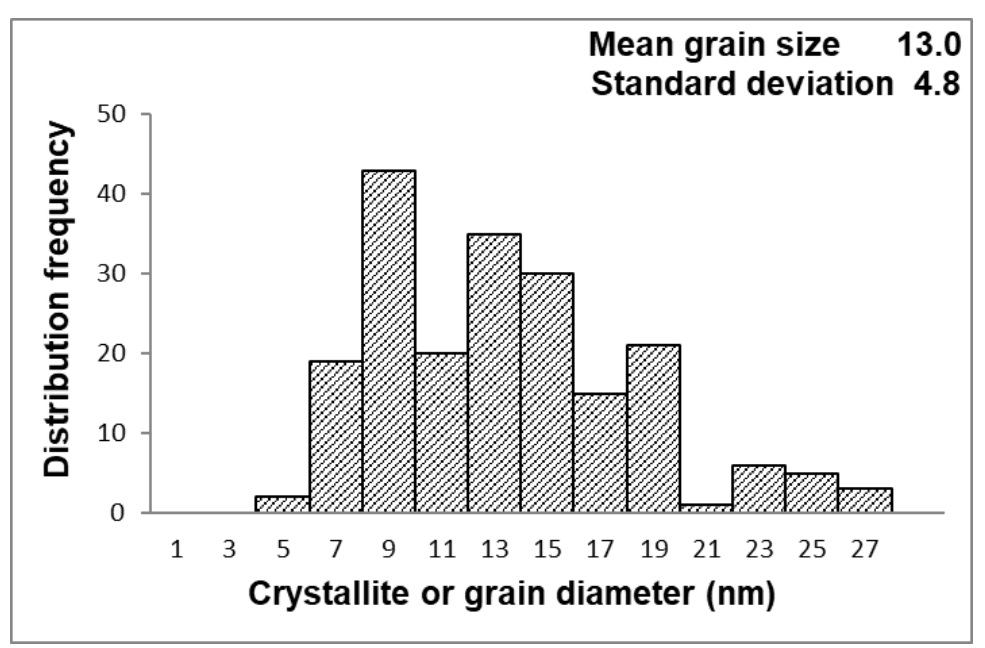

Figure 6: Histogram showing the grain size distribution frequency of Ag NPs obtained from TEM micrograph of 5(a)-Ethanol Precipitation

The obtained results were compared with the finding of others from the same plant source (shown in Table 3) which indicates the formation of smaller and uniform Ag NPs. 
Table 3 Comparison of size and distribution of Ag NPs obtained from our present and previous studies on the same source on the basis of the method of purification and separation.

\begin{tabular}{|c|c|c|c|c|c|c|c|c|}
\hline $\begin{array}{l}\text { N. arbor- } \\
\text { trisitis } \\
\text { extract } \\
\text { source }\end{array}$ & $\begin{array}{l}\text { UV- } \\
\text { Vis }\end{array}$ & XRD & FTIR & SEM & TEM & $\begin{array}{l}\text { Nature of } \\
\text { Ag NPs }\end{array}$ & $\begin{array}{l}\text { Experim } \\
\text { ental } \\
\text { Method } \\
\text { of } \\
\text { Separati } \\
\text { on }\end{array}$ & Reference \\
\hline Leaves & $\begin{array}{l}440 \\
\mathrm{~nm}\end{array}$ & $\begin{array}{c}38.11^{\circ}-111 \\
44.27^{\circ}-200 \\
64.42^{\circ}-220 \\
77.47^{\circ}-311 \\
\text { (size of Ag } \\
\text { NPs from } \\
\text { XRD - } 8.38 \\
\text { nm) }\end{array}$ & $\begin{array}{l}3195-3110 \mathrm{~cm}^{-1} \text { of } \\
\text { bonded }(\mathrm{OH}) \text { or } \\
(\mathrm{NH}) \text { - a form of } \\
\text { flavanal glycosides, } \\
\text { ascorbic acid, tannic } \\
\text { acid, oleanolic acid } \\
\text { \& proteins, etc., } 507 \\
\mathrm{~cm}^{-1} \text { to Ag NP } \\
\text { bonding with } \\
\text { oxygen from }(\mathrm{OH})\end{array}$ & $\begin{array}{c}\text { Spherical } \\
\text { morphology of } \\
\text { Ag NPs coated } \\
\text { with plant } \\
\text { extract }\end{array}$ & $13 \mathrm{~nm}$ & $\begin{array}{l}\text { Spherical, } \\
\text { monodispe } \\
\text { rsed and } \\
\text { uniform }\end{array}$ & $\begin{array}{c}\text { Ethanol } \\
\text { ppt. }\end{array}$ & $\begin{array}{l}\text { From our } \\
\text { present } \\
\text { study }\end{array}$ \\
\hline Flowers & - & $\begin{array}{c}38.1^{\circ}-111 \\
44.4^{\circ}-200 \\
64.8^{\circ}-220 \\
78^{\circ}-311\end{array}$ & $\begin{array}{c}3430 \mathrm{~cm}^{-1}-(\mathrm{OH}) \\
1696 \mathrm{~cm}^{-1}- \\
\text { (carbonyl) } \\
\text { Antioxidants and } \\
\text { phenolic } \\
\text { compounds }\end{array}$ & - & $5-20 \mathrm{~nm}$ & $\begin{array}{l}\text { Spherical } \\
\text { and oval }\end{array}$ & $\begin{array}{l}\text { Centrifug } \\
\text { ation }\end{array}$ & $\begin{array}{l}\text { Gogoi et } \\
\text { al.[49] }\end{array}$ \\
\hline Leaves & $\begin{array}{l}422 \\
\mathrm{~nm}\end{array}$ & $\begin{array}{l}38.3^{\circ}-111 \\
44.5^{\circ}-200 \\
64.6^{\circ}-220 \\
77.5^{\circ}-311\end{array}$ & - & - & $15-20 \mathrm{~nm}$ & $\begin{array}{l}\text { Spherical, } \\
\text { wide range } \\
\text { dispersity }\end{array}$ & $\begin{array}{l}\text { Centrifug } \\
\text { ation }\end{array}$ & $\begin{array}{c}\text { Chandra et } \\
\text { al.[50] }\end{array}$ \\
\hline Seeds & $\begin{array}{l}420 \\
\mathrm{~nm}\end{array}$ & $\begin{array}{c}38.37^{\circ}-111 \\
44.6^{\circ}-200 \\
64.57^{\circ}-220\end{array}$ & $\begin{array}{c}\text { The shift of } 3494 \\
\mathrm{~cm}^{-1} \text { to } 3312 \mathrm{~cm}^{-1} \\
\text { suggests binding of } \\
(\mathrm{OH})\end{array}$ & $50-80 \mathrm{~nm}$ & - & $\begin{array}{l}\text { Spherical } \\
\text { and } \\
\text { polydisper } \\
\text { sed }\end{array}$ & $\mathrm{NA}^{*}$ & $\begin{array}{l}\text { Basu et } \\
\text { al.[48] }\end{array}$ \\
\hline Leaves & $\begin{array}{l}440 \\
\mathrm{~nm}\end{array}$ & - & $\begin{array}{c}\text { disappearance of } \\
3421,2919,2849 \\
\mathrm{~cm}^{-1} \text {, and increase in } \\
\text { intensity of } 1653, \\
1636,1104 \mathrm{~cm}^{-1} \\
\text { peaks after } \\
\text { reduction }\end{array}$ & $28-30 \mathrm{~nm}$ & - & Spherical & $\mathrm{NA}^{*}$ & $\begin{array}{c}\text { Srinivasan } \\
\text { et al.[51] }\end{array}$ \\
\hline Leaves & $\begin{array}{l}397 \\
\mathrm{~nm}\end{array}$ & - & $\begin{array}{l}1621 \mathrm{~cm}^{-1} \text { and } 1318 \\
\mathrm{~cm}^{-1} \text { for silver ions }\end{array}$ & - & $20 \mathrm{~nm}$ & $\begin{array}{l}\text { Spherical, } \\
\text { monodispe } \\
\text { rsed }\end{array}$ & $\mathrm{NA}^{*}$ & $\begin{array}{l}\text { Rout et } \\
\text { al.[52] }\end{array}$ \\
\hline
\end{tabular}

NA*- Not available or mentioned in the article.

\subsection{Conclusions}

In conclusion, current research in silver nanoparticle biosynthesis demands the controlled properties for better performances at a reduced cost. This study achieved the controlled properties of Ag NPs using plant extract route through ethanol precipitation. The UV-Vis and FTIR study demonstrate it as an effective bioreduction and capping source. This study by crystallite size and diffraction parameter measurements using X-ray diffraction confirms the formation of uniform spherical silver nanoparticles which are well supported by TEM micrograhs. The results from the SEM and TEM analysis also corroborates the idea of uniformity in morphology, size and distribution as of Ag NPs that validates the ethanol precipitation as an improved method in plant extract synthesis. We believe this method will provide an alternative way to get biocompatible and size-controlled Ag NPs synthesis based on plant extracts (with the possibility of more uniformity and less variation).

This method advances the current issue of dispersity to a greater extent and provides an option to synthesize smaller, controlled and uniform Ag NPs particles from green biosynthesis approach for medical applications such as antimicrobial agents, bio-scaffolds, therapeutic purpose, and control released and targeted drug delivery. Further in-depth and optimization studies will build on this possibility.

\subsection{Acknowledgments}

We are sincerely thankful to the authorities of Central Department of Chemistry, Tribhuvan University, Nepal for providing all the laboratory facilities and express our gratitude to the Department of Chemistry, Sogang University, South Korea for all the instrumental analysis facilities. I owe great appreciation to AJ Vincelli, University of Massachusetts Dartmouth, the USA for her constructive suggestions in improvising the manuscript.

\section{References}

[1] R. Begum, Z.H. Farooqi, K. Naseem, F. Ali, M. Batool, J. Xiao, and A. Irfan, "Applications of UV/Vis spectroscopy in characterization and catalytic activity of noble metal nanoparticles fabricated in responsive polymer microgels: a review", Crit. Rev. Anal. Chem. Vol. 48, 503-516, 2018. DOI: $10.1080 / 10408347.2018 .1451299$

[2] J. Zheng, P.R. Nicovich, and R.M. Dickson, "High fluorescent Nobel-metal quantum dots", Annu. Rev. Phys. Chem., Vol. 58, $409-431$, 2007. DOI:10.1146/annurev.physchem.58.032806.104546

[3] C.M. Aikens, S.Z. Li, and G.C. Schatz, "From discrete electronic states to plasmons: TDDFT optical absorption properties of Agn (n=10, 20, 35, 56, 84, 120) tetrahedral clusters", J. Phys. Chem. C., Vol. 112,11272-11279, 2008. DOI:10.1021/jp802707r 
[4] K.L. Kelly, E. Coronado, L.L. Zhao, and G.C. Schatz, "The optical properties of metal nanoparticles: the influence of size, shape, and dielectric environment", J. Phys. Chem. B., Vol. 107, 668-677, 2003. DOI:10.1021/jp026731y

[5] M. Hu, J.Y. Chen, Z.Y. Li, L. Au, G.V. Hartland, X.D. Li, M. Marquez, and Y.N. Xia, "Gold nanostructures: engineering their plasmonic properties for biomedical applications", Chem. Soc. Rev., Vol. 35, 1084-1094, 2006. DOI :10.1039/B517615H

[6] H. Wang, D.W. Brandl, P. Nordlander, and N.J. Halas, "Plasmonic nanostructures: artificial biomolecules", Acc. Chem. Res., Vol. 40, 53-62, 2007. DOI:10.1021/ar0401045

[7] A. Moores, and F. Goettmann, “The plasmon band in metal nanoparticles: an introduction to theory and applications", New J. Chem., Vol. 30, 1121-1132, 2006. DOI:10.1039/B604038C

[8] J.P. Guggenbichler, M. Boswald, S. Lugauer, and T. Krall, "A new technology of microdispersed silver in polyurethane induces antimicrobial activity in central venous catheters", Infection, Vol. 27, 16-23, 1999. DOI:10.1007/BF02561612

[9] S. Gurunathana, K.J. Leeb, K. Kalishwaralala, S. Sheikpranbabua, R. Vaidyanathan, and S.H. Eom, "Antiangiogenic properties of silver nanoparticles", Biomaterials, Vol. 30, 6341-6350, 2009. DOI: 10.1016/j.biomaterials.2009.08.008.

[10] Y.H. Hsin, C.F. Chen, S. Huang, T.S. Shih, P.S.Lai, and P.J. Chueh, "The apoptotic effect of nanosilver is mediated by a ROS- and JNK-dependent mechanism involving the mitochondrial pathway in NIH3T3 cells", Toxicol Lett., Vol. 179, 130-139, 2008. DOI:10.1016/j.toxlet.2008.04.015.

[11] R. Foldbjerg, D.A. Dang, and H. Autrup, “Cytotoxicity and genotoxicity of silver nanoparticles in the human lung cancer cell line, A549”, Arch Toxicol., Vol. 85, 743-750, 2011. DOI: 10.1007/s00204-010-0545-5.

[12] M.I. Sriram, S.B. Kanth, K. Kalishwaralal, and S. Gurunathan, "Antitumor activity of silver nanoparticles in Dalton's lymphoma ascites tumor model", Int J Nanomedicine, Vol. 5, 753-762, 2010. DOI: 10.2147/IJN.S11727.

[13] R.W. Sun, C. Rong, N.P.Y. Chung, C.M. Ho, C.L.S. Lin, and C.M. Che, "Silver nanoparticles fabricated in Hepes buffer exhibit cytoprotective activities toward HIV-1 infected cells", Chem Commun (Camb)., Vol. 28, 5059-5061, 2005. DOI: 10.1039/b510984a

[14] H.H. Lara, N.V. Ayala-Nunez, L. Ixtepan-Turrent, and C. Rodriguez-Padilla, "Mode of antiviral action of silver nanoparticles against HIV-1", J. Nanobiotechnology., Vol. 8, 1, 2010. DOI: 10.1186/1477-3155-8-1.

[15] L. Lu, R.W. Sun, R. Chen, C.K. Hui, C.M. Ho, J.M. Luk, G.K. Lau, and C.M. Che, "Silver nanoparticles inhibit hepatitis B virus replication”, Antivir Ther., Vol. $13,253-262,2008$.

[16] L. Sun, A.K. Singh, K. Vig, S.R. Pillai, and S.R. Singh, "Silver nanoparticles inhibit replication of the respiratory syncytial virus", J. Biomed. Biotechnol., Vol. 4, 149-158, 2008. DOI: 10.1166/jbn.2008.012

[17] D. Baram-Pinto, S. Shukla, N. Perkas, A. Gedanken, and R. Sarid, "Inhibition of herpes simplex virus type 1 infection by silver nanoparticles capped with mercapto ethane sulfonate”, Bioconjug Chem., 20, 1497-1502, 2009. DOI: 10.1021/bc900215b.

[18] J.V. Rogers, C.V. Parkinson, Y.W. Choi, J.L. Speshock, and S.M. Hussain, "A preliminary assessment of silver nanoparticle inhibition of monkey pox virus plaque formation", Nanoscale Res Lett., Vol. 3, 129-133, 2008. DOI:10.1007\%2Fs11671-008-9128-2

[19] . Kalishwaralal, S. Barathmanikanth, S.R.K. Pandian, V. Deepak, and S. Gurunathan, "Silver nano - a trove for retinal therapies", J. Control Release., Vol. 145 (2), 76-90, 2010. DOI: 10.1016/j.jconrel.2010.03.022

[20] G. Han, P. Ghosh, and V.M. Rotello, “Functionalized gold nanoparticles for drug delivery," Nanomedicine, Vol. 2(1), 113-123, 2007. DOI: 10.2217/17435889.2.1.113

[21] D.A Giljohann, D.S. Seferos, P.C. Patel, J.E. Millstone, N.L. Rosi, and C.A. Mirkin, “Oligotinucleotide loading determines cellular uptake of DNA-modified gold nanoparticles", Nano. Lett., Vol. 7(12), 3818-3821, 2007. DOI: 10.1021/nl072471q

[22] D.A Giljohann, D.S. Seferos, A.E. Prigodich, P.C. Patel, and C.A. Mirkin, “Gene regulation with polyvalent siRNA-nanoparticles conjugates”, J. Am. Chem. Soc., Vol. 131(6), 2072-2073, 2009. DOI: 10.1021/ja808719p

[23] N.L. Rosi, D.A. Giljohann, C.S. Thaxton, A.K. Lytton-Jean, M.S. Han, and C.A. Mirkin, “Oligonucleotide-modified gold nanoparticles for intracellular gene regulation", Science, Vol. 312(5776), 1027-1030, 2006. DOI:10.1126/science.1125559

[24] D.F. Emerich, and C.G. Thanos, “The pinpoint promise of nanoparticle-based drug delivery and molecular diagnosis", Biomol. Eng., Vol. 23(4), 171-184, 2006. DOI: $10.1016 /$ j.bioeng.2006.05.026

[25] V. Sokolova, and M. Epple, "Inorganic nanoparticles as carriers of nucleic acids into cells", Angew Chem Int Ed Engl., Vol. 47(8), 1382-1395, 2008. DOI: 10.1002/anie.200703039

[26] M.A. Minter, and E.E. Simanek, “Nonviral vectors for gene delivery”, Chem. Rev., 109 (2), 259-302, 2009. DOI: 10.1021/cr800409e.

[27] C.M. Niemeyer, "Nanoparticles, proteins, and nucleic acids: Biotechnology meets material science”, Angew. Chem. Int. Ed. Engl., Vol. 40(22), 4128-4158, 2001. DOI: 10.1002/1521-3773(20011119)40:22<4128::AID-ANIE4128>3.0.CO;2-S.

[28] S.A. Agasti, A. Chompoosor, C.C. You, P. Gosh, C.K. Kim, and V.M. Rotello, "Photoregulated release of caged anticancer drugs from gold nanoparticles", J. Am. Chem. Soc., 131 (16), 5728-5729, 2009. DOI: 10.1021/ja900591t.

[29] J.L. Vivero-Escoto, I.I. Slowing, C.W. Wu, and V.S.Y. Lin, "Photoinduced intracellular controlled released drug delivery in human cells by gold-capped mesoporous silica nanosphere", J. Am. Chem. Soc., Vol. 131(10), 3462-3463, 2009. DOI: 10.1021/ja900025f.

[30] M. Oishi, J. Nakaogami, T. Ishii, and Y. Nagasaki, "Smart PEGylated gold nanoparticles for the cytoplasmic delivery of siRNA to induce enhanced gene silencing", Chem. Lett., Vol. 35, 1046-1047, 2006. DOI: 10.1246/cl.2006.1046

[31] W.J. Song, J.Z. Du, T.M. Sun, P.Z. Zhang, and J. Wang, "Gold nanoparticles capped with polyethyleneimine for enhanced siRNA delivery", Small, Vol. 6(2), 239-246, 2010. DOI: 10.1002/smll.200901513

[32] J.L. Elechiguerra, J.L. Burt, J.R. Morones, A. Camacho-Bragado, X. Gao, H.H. Lara, and M.J. Yacaman, "Interaction of silver nanoparticles with HIV-1", J. Nanobiotechnology., 3, 6, 2005. DOI: 10.1186/1477-3155-3-6

[33] S. Pal, Y.K. Tak, and J.M. Song, "Does the antibacterial activity of silver nanoparticles depend on the size of the nanoparticle? A study of the gramnegative bacterium Escherichia coli", Appl. Environ. Microbiol., Vol. 73, 1712, 2007. DOI: 10.1128/AEM.02218-06 
[34] S. Agnihotri, S. Mukherji, and S. Mukherji, "Size controlled silver nanoparticles synthesized over the range of 5-100 nm using the same protocol and their antibacterial efficiacy", RSC Adv., Vol. 4, 3974-3983, 2014. DOI: 10.1039/C3RA44507K

[35] A.J. Kora, R.B. Sashidhar, and J. Arunachalam, "Gum kondagogu (Cochlospermum gossypium): a template for the green synthesis and stabilization of silver nanoparticles with the antibacterial application", Carbohydrate Polymers., Vol. 82, 670-679, 2010. DOI: 10.1016/j.carbpol.2010.05.034

[36] M.H. El-Rafie, M.E. El-Nagger, M.A. Ramadan, M.M.G. Fouda, S.S. Al Deyab, and A. Hebeish, "Environmental synthesis of silver nanoparticles using hydroxypropyl starch and their characterization", Carbohydrate Polymers, Vol. 86, 630-635, 2011. D0I: 10.1016/j.carbpol.2011.04.088

[37] A.M. Fayaz, K. Balaji, P.T. Kalaichelvan, and R. Venkatesan, "Fungal based synthesis of silver nanoparticles-an effect of temperature on the size of nanoparticles", Colloids Surf. B.: Biointerfaces., Vol. 74, 123-126, 2009. DOI: 10.1016/j.colsurfb.2009.07.002

[38] N. Ahmad, and S. Sharma, "Green synthesis of silver nanoparticles using extracts of Ananas comosus", Green \& Sustainable Chemistry, Vol. 2, 141-147, 2012. DOI: $10.4236 /$ gsc.2012.24020

[39] A.M. Awwad, N.M. and Salem, O.A. "Abdeen, Green synthesis of silver nanoparticles using carob leaf extract and its antibacterial activity", Int. J. of Indust. Chem., Vol. 4, 29, 2013. DOI:10.1186/2228-5547-4-29

[40] A.M. Awwad, and N.M. Salem, “Green synthesis of silver nanoparticles by Mulberry leaves extract”, J. Nanosci. \& Nanotech., Vol. 2(4), 125-128, 2012. DOI: $10.5923 /$ j.nn.20120204.06

[41] K.S. Prasad, D. Pathak, A. Patel, P. Dalwadi, R. Prasad, P. Patel, and K. Selvaraj, "Biogenic synthesis of silver nanoparticles using Nicotiana tobaccum leaf extract and study of their antibacterial effect", Afr. J. Biotechnol., Vol. 10, 8122-8130, 2010. DOI: 10.5897/AJB11.394

[42] J. Umashankar, D. Inbakandam, T.T. Ajithkimar, and T. Balasubramania, "Mangrove plant, Rhizophora mucronata (Lamk, 1804) mediated one pot green synthesis of silver nanoparticles and its antibacterial activity against aquatic pathogens", Bio. Med. Central., Vol. 8, 11, 2012. DOI: 10.1186\%2F2046-90638-11

[43] M. Amin, F. Anwar, M.R. Janjua, M.A. Iqbal, and U. Rashid, “Green synthesis of silver nanoparticles through reduction with Solanum xanthocarpum L. berry extract: characterization, antimicrobial, and urease inhibitory activities against Helicobacter pylori", Int. J. Mol. Sci., Vol. 13(8), 9923-9941, 2012. DOI: $10.3390 / \mathrm{ijms} 13089923$.

[44] K. Murugan, B. Senthilkumar, D. Senbagam, and S. Al-Sohailbani, "Biosynthesis of silver nanoparticles using Acacia leucophloea extract and their antibacterial activity", Int. J. Nanomedicine, Vol. 9, 2431-2438, 2014. DOI: 10.2147/IJN.S61779.

[45] N. Sanchooli, S. Saeidi, H.K. Barani, and E. Sanchooli, "In vitro antibacterial effects of silver nanoparticles synthesized using Verbena officinalis leaf extract on Yersinia ruckeri, Vibrio cholera, and Listeria monocytogenes", Iran J Microbiol., Vol. 10(6), 400-408, 2018. PMCID: PMC6414745

[46] A. Gupta, A.R. Koirala, B. Joshi, S. Khanal, B. Gupta, and N. Parajuli, "Synthesis of silver nanoparticles using leaves of Taraxacum officinale and their antimicrobial activities", Adv. Sci. Eng. Med., Vol. 9(3), 221-228, 2017. DOI: 10.1166/asem.2017.1983

[47] V.K. Dhingra, T.R. Seshadri, and S.K. “Mukerjee, Carotenoid glycosides of Nyctanthes arbor-tristis Linn”, Indian. J. Chem., Vol. 14B, 231-232, 1976.

[48] S. Basu, P. Maji, and J. Ganguly, "Rapid green synthesis of silver nanoparticles by aqueous seed extracts of Nyctanthes arbor-tristis", Appl. Nanosci., Vol. 6 (1), 1-5, 2016. DOI: 10.1007/s13204-015-0407-9

[49] N. Gogoi, P.J. Babu, C. Mahanta, and U. Bora, "Green synthesis and characterization of silver nanoparticles using alcoholic flower extract of Nyctanthes arbor-tristis and in vitro investigation of their antibacterial and cytotoxic activities", Mater. Sci. Eng. C., Vol. 46, 463-469, 2014. DOI: 10.1016/j.msec.2014.10.069.

[50] A. Chandra, and S. Garg, "Effect of varying concentration of herbal extract of Nyctanthes arbor-tristis leaf on synthesis of silver nanoparticles and its evaluation", Int. J. Pharm. Pharm. Sci., Vol. 7(7), 143-147, 2015.

[51] S. Srinivasan, K. Sujithra, U. Murgunathan, R. Murali, C. Navetha, and D. Indumathi, "Green synthesis and characterization of silver nanoparticles using Nyctanthes arbortristis Linn leaf extract and their antibacterial activity", Focus on Sciences, Vol. 3(4), 9-14, 2017. DOI: 10.21859/focsci-03041468.

[52] A. Rout, P.K. Jena, D. Sahoo, U.K. Parida, and B.K. Bindhani, "Green synthesis and characterization of silver nanoparticles for antimicrobial activity against burn wounds contaminating bacteria”, Int. J. Nanosci., Vol. 13(2), 1450010, 2014. DOI:10.1142/S0219581X14500100

[53] M. Sastry, K.S. Mayya, and K. Bandyopadhyay, "pH Dependent changes in the optical properties of carboxylic acid derivatized silver colloidal particles", Colloid Surf. A. Physicochem. Eng. Asp., Vol. 127, 221-228, 1997. DOI: 10.1016/s0927-7757(97)00087-3

[54] K.G. Stamplecoskie, and J.C. Scaiano, "Light emitting diode irradiation can control the morphology and optical properties of silver nanoparticles", J. Am. Chem. Soc., Vol. 132(6), 1825-1827, 2010. DOI: 10.1021/ja910010b

[55] V.K. Vidhu, S.A. Aromal, and D. Philip, "Green synthesis of silver nanoparticles using Macrotyloma uniflorum”, Spectrochim Acta A Biomol Spectros, Vol. 83(1), 392, 2011. DOI: 10.1016/j.saa.2011.08.051.

[56] R.W. Raut, N.S. Kolekar, J.R. Lakkula, V.D. Mendhulkar, and S.B. Kashid, "Extracellular synthesis of silver nanoparticles using dried leaves of Pongamia pinnata (L) pierre", Nano-Micro Letters., Vol. 2(2), 106-113, 2010. DOI: 10.5101/nml.v2i2.p106-113

[57] G. Li, D. He, Y. Qian, B. Guan, S. Gao, Y. Cui, K. Yokoyama, and L. Wang, "Fungus-mediated green synthesis of silver nanoparticles using Aspergillus terreus", Int. J. Mol. Sci., Vol. 13(1), 466-476, 2012. DOI: 10.3390\%2Fijms13010466

[58] T. Theivasanthi, and M. Alagar, "Electrolytic synthesis and characterization of silver nanopowder", Nano Biomed. Eng., Vol. 4, 58-65, 2012. DOI: 10.5101/nbe.v4i2.p58-65

[59] K. Shameli, M.B. Ahmad, E.A.J. Al-Mulla, N.A. Ibrahim, P. Shabanzadeh, A. Rustaiyan, Y. Abdollahi, S. Bagheri, S. Abdolmohammadi, M.S. Usman, and M. Zidan, "Green biosynthesis of silver nanoparticles using Callicarpa maingayi stem bark extraction", Molecules, Vol. 17(7), 8506-8517, 2012. DOI: $10.3390 /$ molecules17078506.

[60] K. Shameli, M.B. Ahmad, S.D. Jazayeri, P. Shabanzadeh, P. Sangpour, S. Jahangirian, and Y. Gharayebi, "Investigation of antibacterial properties silver nanoparticles prepared via the green method", Chem. Cent. J., Vol. 6, 73, 2012. DOI: 10.1186/1752-153X-6-73

[61] T. Theivasanthi, and M. Alagar, “Nano sized copper particles by electrolytic synthesis and characterization”, Int. J. Phys. Sci., Vol. 6(15), 3662-3671, 2011. DOI: 10.5897/IJPS10.116 